\title{
THE INFLUENCE OF THE BRAKE PAD SURFACE MACHINING AND FINISHING ON ITS FRICTION PERFORMANCE - EXAMINED BY INERTIA BRAKE DYNAMOMETER TESTING
}

The article describes the influence of brake pads surface machining and finishing on their friction characteristics. It shows the methods of machining and finishing of the brake pads surface and their influence on noise emission and performance. It shows the brake dynamometer test results obtained on three brake pads which have three different types of surface modification and their detailed analysis and comparison.

\section{INTRODUCTION}

The machining modification of the brake pads shape is used by many brake components manufacturers all over the world. The main purpose of machining and finishing the shape of the brake pads is to reduce their squeal noise emission. There are four common methods of machining and finishing brake pads, first method is grinding the friction surface, the purpose of which is to prepare the pad friction surface so it is not rough and rugged, this helps the brake pad to burnish quicker and prevents brake disc grooving. An exemplary grinded brake pad is shown on pictures 1 and 2 .

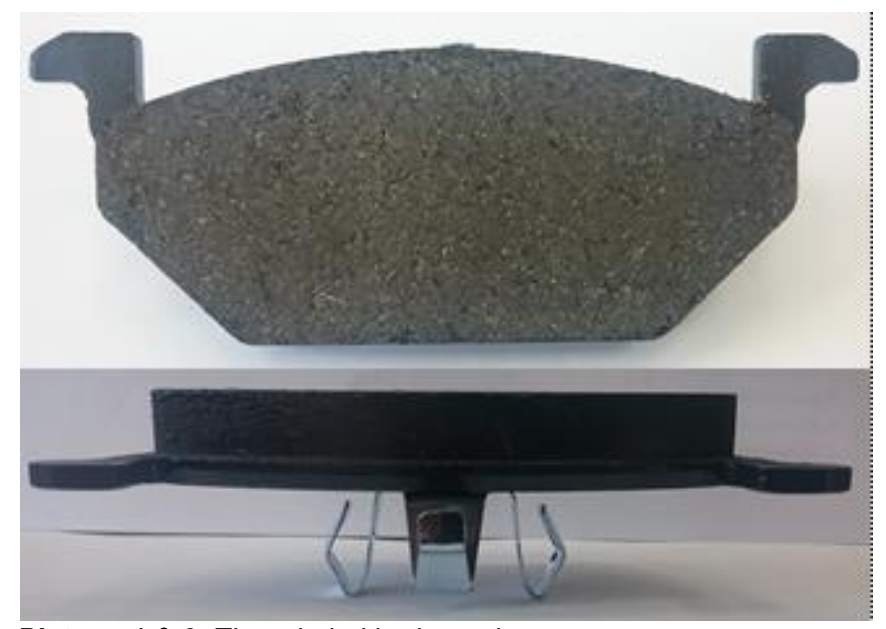

Picture. $1 \&$ 2. The grinded brake pad.

The second machining and finishing method is "chamfering" the edges of the brake pads. The chamfers are made perpendicularly to the brake disc rotation direction. This eliminates a sharp edge between the brake pad and disc contact, in effect it helps cleaning the pad edge of brake dust and reduces the noise emission. Also the brake pad should burnish quicker when it is chamfered because the work surface is lower. Chamfered brake pads are also grinded. The example of a chamfered brake pad is shown on pictures 3 and 4 .

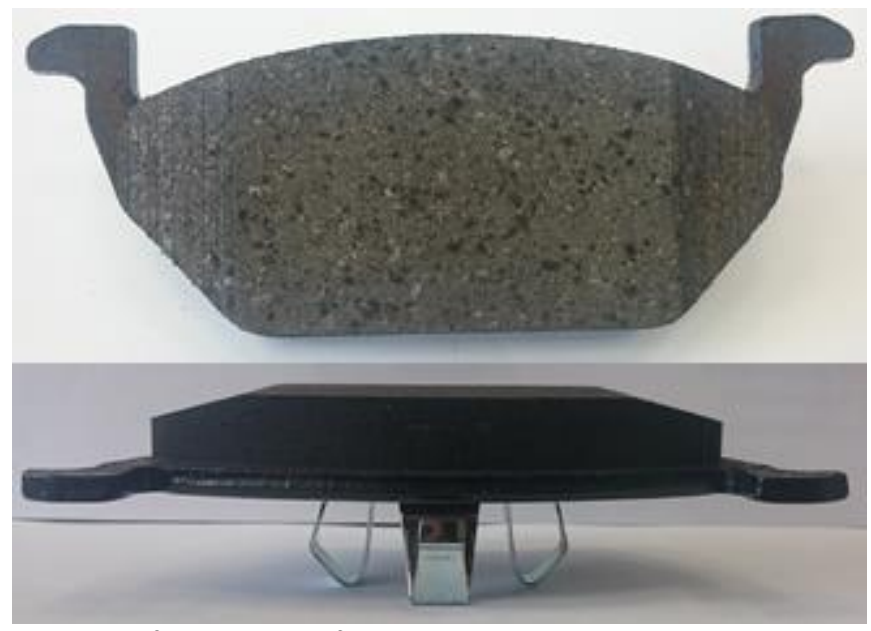

Picture. 3 \& 4. The chamfered brake pad.

The third option for machining and finishing of brake pads is making a "slot". This is a grove made in the middle of the brake pad perpendicularly to the brake disc rotation direction. The purpose of this is to make a free area in the middle of the brake working surface in order to allow an easier escape of brake gases, dust and wear particles. This helps cleaning the braking surface and in effect reduces the noise squeal emission. Slotted brake also has to be grinded at first. An exemplary slotted brake pad is shown on pictures 5 and 6.

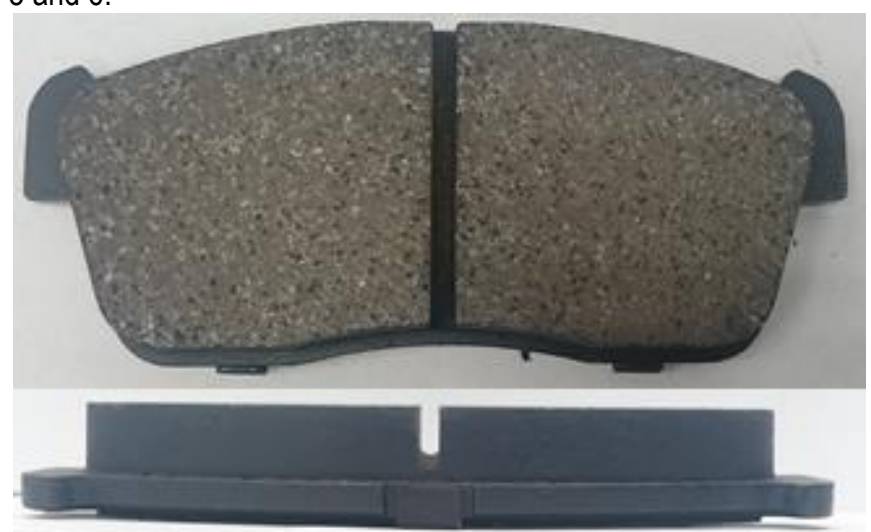

Picture. 5 \& 6. The slotted brake pad. 


\section{Eksploatacja i testy}

Fourth machining and finishing method is a fusion of all three previous methods, so it is a grinded, slotted and chamfered pad. This is a version that combines all the benefits in one brake pad. An example of this is shown on pictures 7 and 8 .

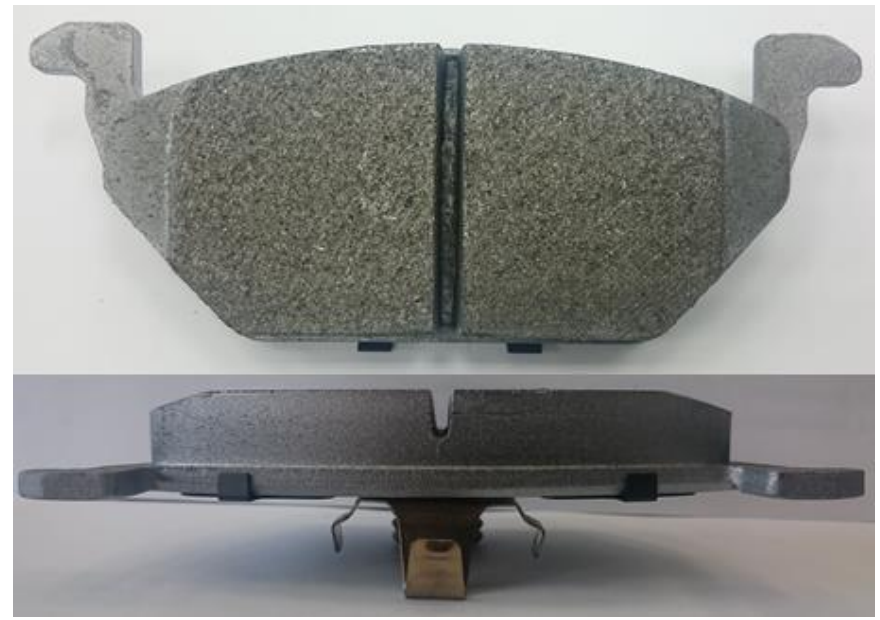

Picture. 7 \& 8. The chamfered and slotted brake pad.

The reduction of squeal noise emission is the main reason for machining and finishing brake pads, but it also has its effect on their friction and structural characteristics. Making chamfers on brake pads allows the brake gasses and dust to escape form between the pad and disc easier and that should increase its performance in high speed and temperature brake applications. Slotting the brake pad also should make the brake gases and dust escape easier and also it unloads tension in the middle of friction material and prevents it from cracking and disintegrating. The purpose of this article is to check the influence of making a machining and finishing modifications of brake pads on their friction characteristics.

\section{THE TEST}

\subsection{The test objects}

The test was conducted on a front brake disc from a 2001' Volkswagen Golf IV generation, it is a representative of "C" vehicle segment, a middle size vehicle. The technical data of the tested brake vehicle is shown in table 1.

Tab. 1. Test vehicle technical specification.

\begin{tabular}{|c|c|}
\hline Vehicle Make & Volkswagen \\
\hline Vehicle Model & Golf MKIV (1J1) \\
\hline Vehicle Year & $1997-2003$ \\
\hline Vehicle Engine & $1.6\left[\mathrm{dm}^{3}\right] \mathrm{R} 4$ \\
\hline Power [kW |BHP] & $77 \mid 105$ \\
\hline Torque [Nm] & 148 \\
\hline Vmax [km/h] & 192 \\
\hline Empty weight [kg] & 1145 \\
\hline Gross weight $[\mathrm{kg}]$ & 1750 \\
\hline Tyre dynamic rolling radius $[\mathrm{mm}]$ & 308 \\
\hline Front wheel moment of inertia $\left[\mathrm{kg} \cdot \mathrm{m}^{2}\right]$ & 65 \\
\hline
\end{tabular}

The tested vehicle is equipped with front floating type disc brake. The brake calliper has one piston and it is guided by two brake pins which are mounted in rubber guides. The guide pins are mounted directly to the vehicle suspension knuckle. The brake disc is externally ventilated, the brake pads are mounted in the brake calliper via mounting springs. The tested disc brake mounted on the test bench is shown on picture number 7 and technical data is shown in table number 2.

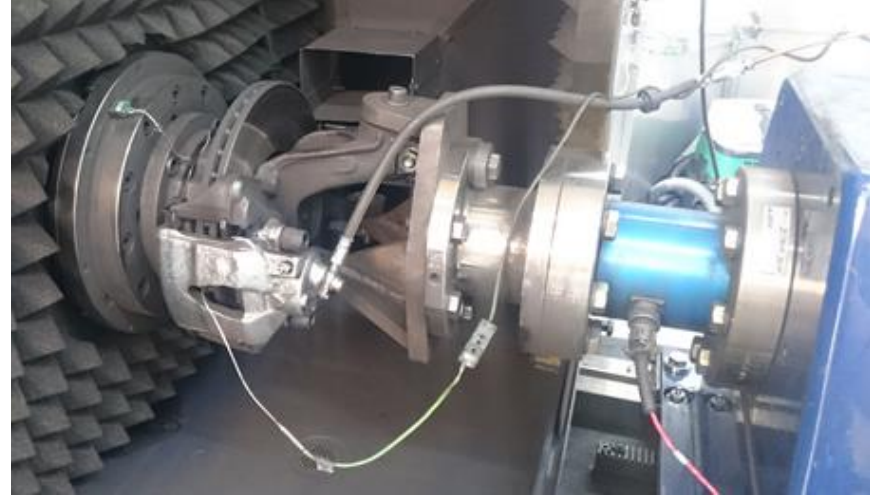

Picture. 7. The test brake assembled on the dynamometer.

Tab. 2. Test tested disc brake technical specification.

\begin{tabular}{|c|c|}
\hline Brake type & Floating \\
\hline Number of pistons & 1 \\
\hline Piston diameter [mm] & 52 \\
\hline Brake disc type & Externally ventilated \\
\hline Brake disc diameter [mm] & 280 \\
\hline Brake disc thickness [mm] & 22 \\
\hline Brake disc effective radius [mm] & 225 \\
\hline Friction surface height [mm] & 55 \\
\hline Brake pads height [mm] & 54.65 \\
\hline Brake pads length [mm] & 146 \\
\hline Brake pads thickness [mm] & 19,2 \\
\hline
\end{tabular}

The tests were conducted on three exactly the same brake pads sets, from the same manufacturer and made from the same friction material compound, the only difference were the machining and finishing process made. First test samples were as they came from the box, send had chamfers machined, third had slots made. The brake disc used was a popular aftermarket manufacturer and new for every set of brake pads. All of the tests were conducted on the same brake calliper and mounting bracket.

\subsection{The testing equipment}

In order to make sure that the test conditions were repeatable and the same as much as possible for every brake pads modification, the test had was conducted in laboratory condition in BOSMAL Automotive Research and Development Institute Ltd using a professional brake test station. The brakes were tested on an Inertia brake Dynamometer, LINK model M3000. The dynamometer is shown on picture 9.

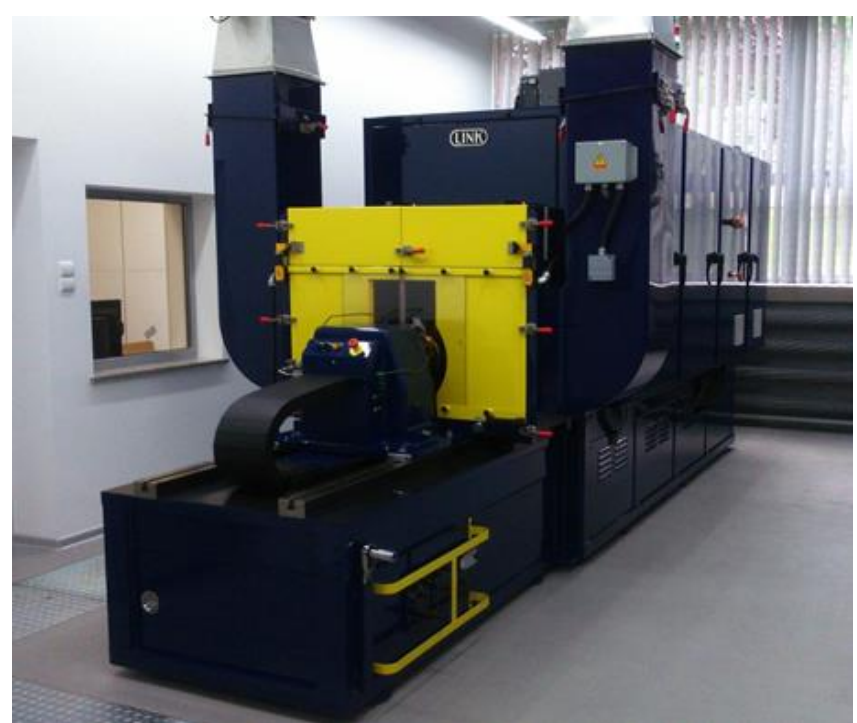

Picture. 9. The LINK M3000 Inertia Brake Dynamometer in BOSMAL Automotive Research and Development Institute Ltd. 
The dynamometer is adapted to test the drum and disk brake systems of all kind, in real scale in range of functional tests, noise and durability. The dynamometer allows to test a whole brake from an actual vehicle, the brake can be even mounted with the vehicles suspension if there is a need for it. Technical specification and capabilities of the BOSMAL LINK M3000 Dyno are shown in table 3.

Tab. 3. The LINK M3000 specification.

\begin{tabular}{|c|c|}
\hline DC Drive Motor Power & $186 \mathrm{~kW}$ \\
\hline Rotational speed range & $0 \div 2500 \mathrm{rpm}$ \\
\hline Maximum braking torque & $5650 \mathrm{Nm}$ \\
\hline Minimum simulated moment of inertia & $5 \mathrm{kgm}^{2}$ \\
\hline Minimum mechanical moment of inertia & $42,7 \mathrm{kgm}^{2}$ \\
\hline Maximum mechanical moment of inertia & $128 \mathrm{kgm}^{2}$ \\
\hline Maximum simulated moment of inertia & $250 \mathrm{kgm}$ \\
\hline Maximum brake pressure & $20 \mathrm{MPa}$ \\
\hline Maximum pressure ramp rate & $100 \mathrm{MPa} / \mathrm{sec}$ \\
\hline
\end{tabular}

\subsection{The test procedure}

The purpose of the test was to compare the friction characteristics of three brake pads sets which were subjected to a different machining and finishing methods: grinded, chamfered and slotted. There were four test sections made on each of test samples sets, burnishing, speed section, cold braking section and high temperature section.

Burnishing section is a series of 222 cycles with alternating braking fluid pressures with the same initial and final speed, the purpose of this test section is to check if the modification actually reduce the pad running-in time

The speed/pressure section is a series of 40 brake applications for different vehicle speeds and pressure values, this is to check how the brake pads cope with different speed/pressure conditions.

The cold section is a series of 5 brake application simulating the highway conditions, where the brake is cold due to lack of usage for a long time and then suddenly has to reduce very high vehicle speed in short time, so with large deceleration level.

High temperature section is a series of 15 cycles with rising up to $600^{\circ} \mathrm{C}$ temperature, the purpose of this section is to compare pads performance in different temperatures.

For every test cycle the following signals were measured: Braking torque, rotational speed of the brake disc, temperature of the disc and pad, the pressure in the brake system. Based on those signals and on the geometry of the brake disc and the brake calliper the friction coefficient was calculated. Also the wear of the brake pads was measured.

The vehicles test parameter were calculated for the maximum permissible vehicle mass. The wheel dynamic radius was calculated according to manufacturer's factory data.

Each tested brake pad compound was new in the beginning of the test. The brake discs used for testing were new for every test.

\section{THE TEST RESULTS}

\subsection{Burnish test section}

The purpose of the burnish test section was to check how different type of surface finish is influencing brake pads ability to burnish. The results of burnishing test section are shown on graph number 1 .

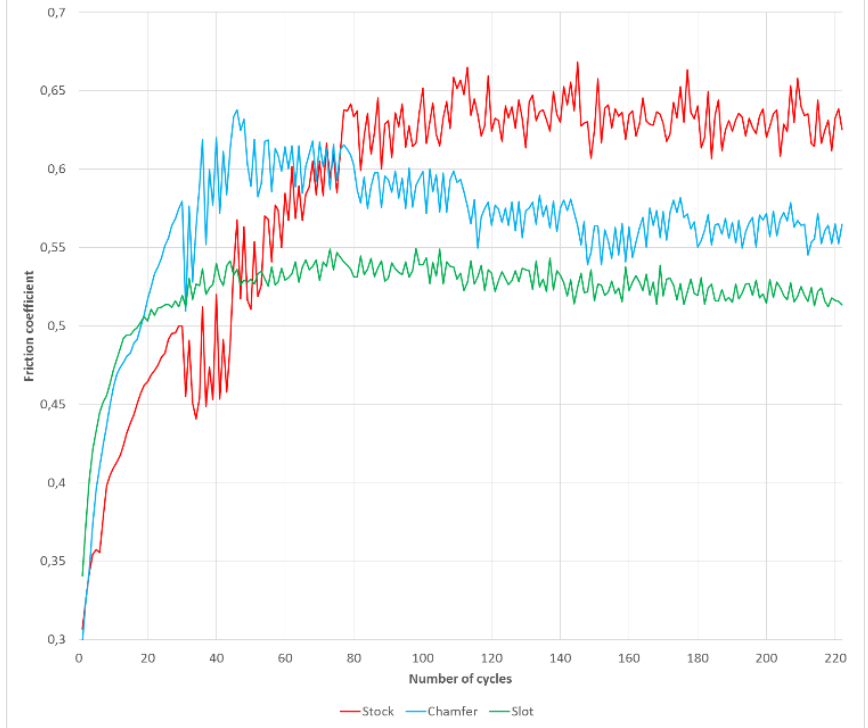

Graph. 1. Burnishing phase test results.

The unmodified "Stock" brake pads take more time to burnish due to their largest work surface area but for the same reason when they are properly burnished they achieve the highest friction coefficient values. Brake pads with chamfers are burnishing quicker than stock pads and they reach the highest friction coefficient value earlier but from then the friction coefficient is starting to fade, probably because the working area is smaller and they are getting polished and glazed. Different situation was observed with brake pads that had slots machined in the friction material, they were burnishing quickly but when they have reached the highest friction coefficient value it has stabilised and settled till the end of the section. The friction coefficient values are shown in table number 4.

Tab. 4. Burnishing phase test results.

\begin{tabular}{|l|c|c|c|}
\hline Test sample & Stock & Chamfer & Slot \\
\hline MIN $\boldsymbol{\mu}$ & 0.307 & 0.298 & 0.341 \\
\hline MAX $\boldsymbol{\mu}$ & 0.668 & 0.638 & 0.549 \\
\hline AVERAGE $\boldsymbol{\mu}$ & 0.586 & 0.564 & 0.522 \\
\hline Dispersion & 0.362 & 0.339 & 0.209 \\
\hline
\end{tabular}

The average friction coefficient value is the highest for stock brake pads, it is a bit lower for chambered pads and for slotted pads it is significantly lower. Also maximum value is biggest for stock pads. The dispersion in friction coefficient values is the smallest for slotted brake pads and the biggest for stock which are the most stable in their friction coefficient.

\subsection{Speed/pressure test section.}

The purpose of this test section was to put the test object under different vehicle velocity and brake fluid pressure conditions. The results of speed/pressure test section are shown on graph number 2 and in table number 5 . 


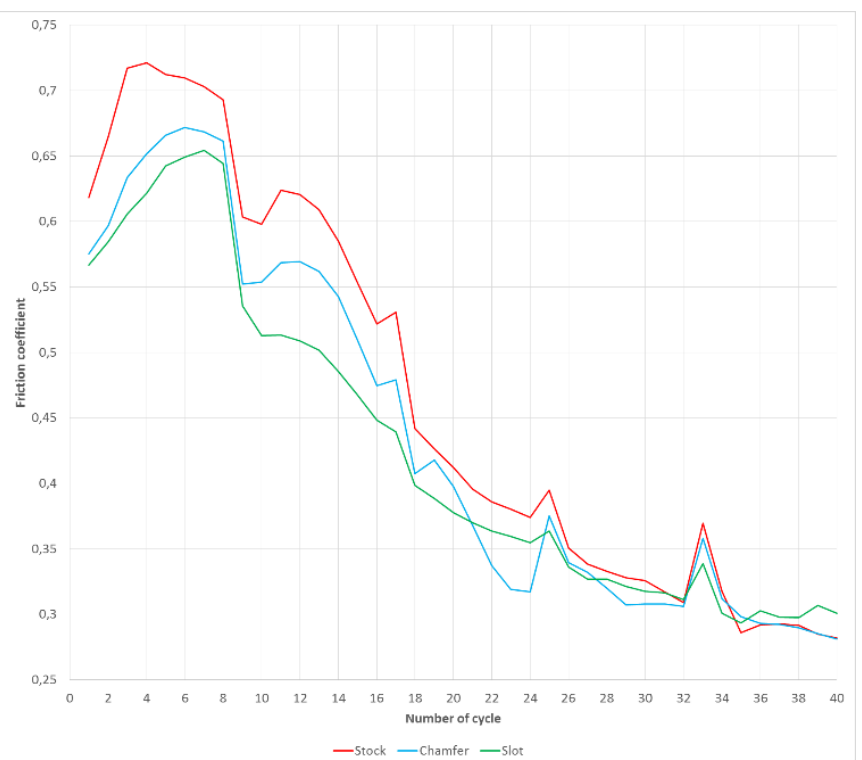

Graph. 2. Speed/pressure phase test results.

The unmodified "Stock" brake pads seem to cope best with the test conditions. The friction coefficient is the highest from the three test samples but the chamfered and slotted brake pads have more stable friction coefficient and that gives the driver a better feel and confidence when braking. Also the dispersion between highest and lowest friction coefficient vales are lower for chamfered and slotted brake pads, for chamfered brake pads it was 0.39 , for slotted 0.36 while stock pads had 0.44 difference in the friction coefficient.

Tab. 5. Speed/pressure phase test results.

\begin{tabular}{|l|c|c|c|}
\hline Test sample & Stock & Chamfer & Slot \\
\hline MIN $\mu$ & 0.282 & 0.281 & 0.294 \\
\hline MAX $\mu$ & 0.721 & 0.672 & 0.654 \\
\hline AVERAGE $\mu$ & 0.468 & 0.438 & 0.426 \\
\hline Dispersion & 0.439 & 0.390 & 0.361 \\
\hline
\end{tabular}

The maximum friction coefficient value vas obtained for stock brake pads, but they also had one of the lowest values and the dispersion was very big reaching 0.721 . The smallest dispersion was obtained on slotted brake pads, they also had the biggest minimum friction coefficient values but the smallest maximum. Average friction coefficient values were comparable.

\subsection{Cold test section}

The purpose of cold test section was to simulate a test conditions when a cold brake pads have to decelerate the vehicle with high braking torque. Cold test section results are shown on graph number 3 and table number 6 .

All the tested brake pads had similar friction coefficient course. Test brake pads with slots have a slight advantage in this test over other test objects. Their friction coefficient is considerably higher and it has the smallest dispersion. Stock brake pads seem to underper- form in this test in comparison with other test objects. The modification made in the chamfered and slotted pads really seem to give an effect in those conditions, long and high heat generation brake applications are easier to cope for them. Chamfered and slotted pads have the highest minimum, maximum and average friction coefficient.

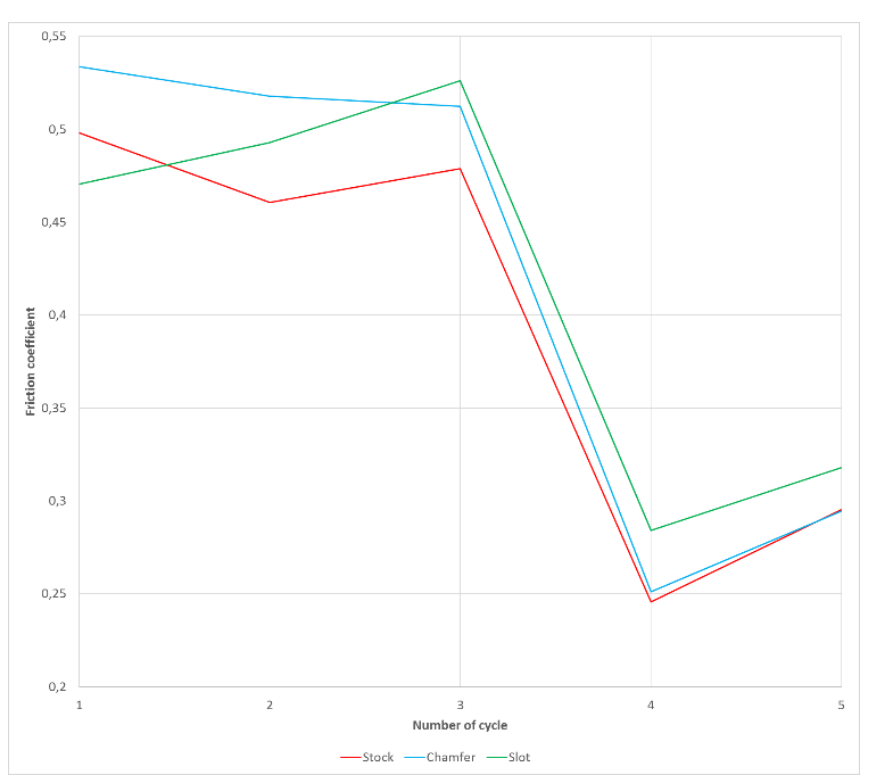

Graph. 3. Cold phase test results.

Tab. 6. Cold phase test results.

\begin{tabular}{|l|c|c|c|}
\hline Test sample & Stock & Chamfer & Slot \\
\hline MIN $\mu$ & 0.246 & 0.251 & 0.284 \\
\hline MAX $\mu$ & 0.498 & 0.534 & 0.526 \\
\hline AVERAGE $\mu$ & 0.396 & 0.422 & 0.418 \\
\hline Dispersion & 0.252 & 0.282 & 0.242 \\
\hline
\end{tabular}

\subsection{Temperature test section}

Temperature section purpose is to put the friction material under brake applications with high deceleration and speed and with increasing temperature after each cycle. This is commonly known as "FADE", because usually with temperature brake pads are losing friction coefficient values. The course of the friction coefficient is similar in shape for all of the tested brake pads. In the first couple of brake applications all three test brake pads share nearly identical friction coefficient values, although after they reach about $300^{\circ} \mathrm{C}$ the graph courses are beginning to split, in the middle part of the test the slotted brake pads have the smallest friction coefficient decrease, stock are in the middle and chamfered have the biggest loss in friction coefficient. In the third part when the brake reaches nearly $450^{\circ} \mathrm{C}$ stock brake pads have the biggest friction coefficient fading effect, while stock and chamfered have obtained similar results. Brake pads with machined chamfered and slots are coping better in high temperature test conditions, it seems that modification allow the gases to escape from the brake pads and disc contact area, stock brake pads are suffering in high temperature due to brake gases and dust accumulation between friction surfaces. The temperature fade test section test results are shown on graph number 4 and in table number 7 . 


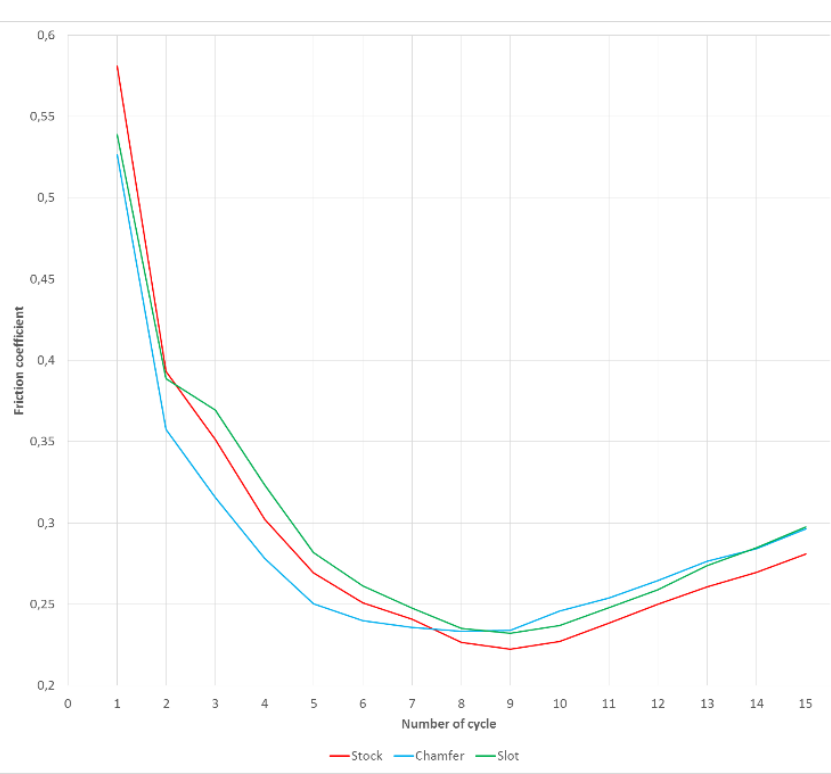

Graph. 4. Temperature phase test results.

The stock brake pads have achieved the lowest friction coefficient value in the temperature test section -0.223 , while chamfered and slot did a bit better achieving 0.233 and 0.232 . Stock test samples achieved the largest friction coefficient value -0.581 , chamfer and slot achieved lower values and again similar to each other 0.527 and 0.539 . Slotted brake pads had the largest average friction coefficient values -0.299 , stock were just behind with 0.291 , and the lowers was obtained for chamfered pads -0.286 . Stock pads had the largest friction coefficient dispersion 0.358 and that means they are the least stable.

Tab. 7. Temperature phase test results.

\begin{tabular}{|l|c|c|c|}
\hline Test sample & Stock & Chamfer & Slot \\
\hline MIN $\mu$ & 0.223 & 0.233 & 0.232 \\
\hline MAX $\mu$ & 0.581 & 0.527 & 0.539 \\
\hline AVERAGE $\mu$ & 0.291 & 0.286 & 0.299 \\
\hline Dispersion & 0.358 & 0.293 & 0.307 \\
\hline
\end{tabular}

\subsection{Test results summary}

The brake pad with no shape and friction surface modification "stock" have underperformed in comparison with modified test subjects. Despite achieving the highest friction coefficient values in the burnish test section it has less friction coefficient stability and it needs a lot more brake applications and time to get burnished completely. In the speed /pressure test section the situation is similar, unmodified pads have achieved highest friction coefficient values throughout the whole test, but they also had the biggest friction coefficient dispersion and a very big disorder in its course. Irregular friction coefficient might not give the vehicle driver a good feel of the brakes. In the cold application test section stock pads have underperformed significantly. The friction coefficient is lower than modified pads in nearly all of the test cycles. It seems that unmodified brake pads do not cope well with long and high heat emission brake applications. In the temperature section stock pads have also achieved the worst result, their friction coefficient have faded the most of three test objects. It looks like solid friction surface causes a brake gases and dust build up between brake pads and disc and that affects braking ability of the whole brake. The unmodified brake pad after the test is shown on picture number 10.

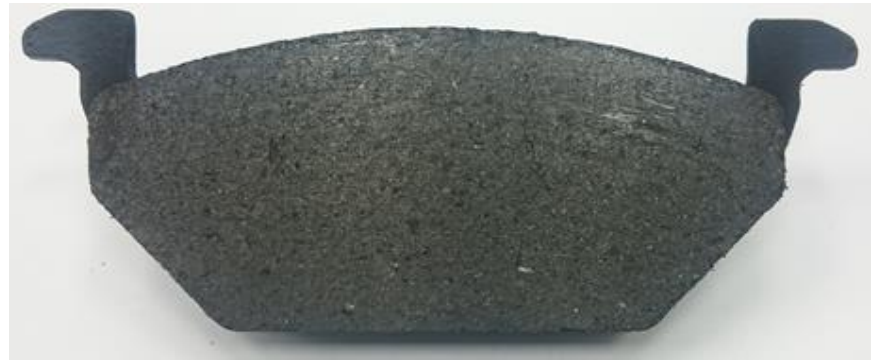

Picture. 10. The stock brake pad after the tests.

The test samples with chamfers machined on the edges of friction surfaces have performed better in the conducted tests than unmodified pads. In the burnishing test section they have reached very high friction coefficient values and very quickly, friction coefficient is blinding up fast and then it is settling through the test which means it has an ability to burnish quicker, also it is stable. In the speed/pressure test section it reaches lower friction coefficient than stock but higher than slotted pad, but it is more stable and the dispersion is not that high like for stock test pads. In the cold brake application section chamfered pads did a lot better than unmodified pads, but not as good as slotted pads. It looks like machining chamfers on the friction surface edged does improve its performance in long high deceleration braking. In the temperature/fade section pads with chamfers have performed worse than stock and slotted pads in the first test part but in the second part, in very high temperatures it has achieved the highest friction coefficient values. Machining chamfers in brake pads seem to improve their braking ability in very high heat conditions. The brake pad with chamfers machined after the test is shown on picture 11.

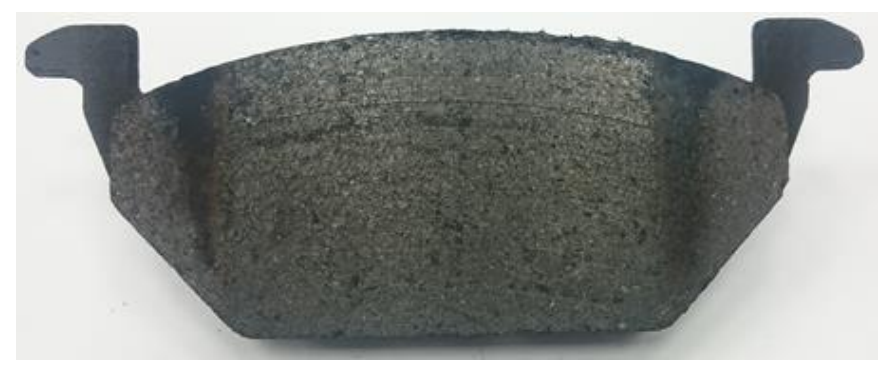

Picture. 11. The chamfered brake pad after the test.

The brake pads with slots machined in the middle of the friction area seem to cope really good with all test conditions, they have obtained the best results for the three modifications. In the burnishing test section they have obtained the highest friction coefficient increase, reached the maximum value in the shortest time and it was the most stable. They have burnished in the shortest time in comparison with stock and chamfered. The friction coefficient values are the lowest from the three, but they are very stable and settled and that is important because it gives the vehicle driver good feel and confidence of the brakes. In the speed/pressure test sections slotted brake pads have reached the lowest friction coefficient form the tested friction materials, but it was one again the most stable and it has reached the lower friction coefficient dispersion. In the cold brake application section slotted brake pads have achieved the highest brake coefficient values and the smallest disparity. This brake pads modification is coping with those test conditions really good. In the temperature test section slotted brake pads have achieved the best result, they have the highest friction coefficient values in all of high temperature cycles, and it is the most stable, the friction coefficient dispersion is the small. The brake pad with slot machined in the middle of the friction area the test is shown on picture number 12 . 


\section{Eksploatacja i testy}

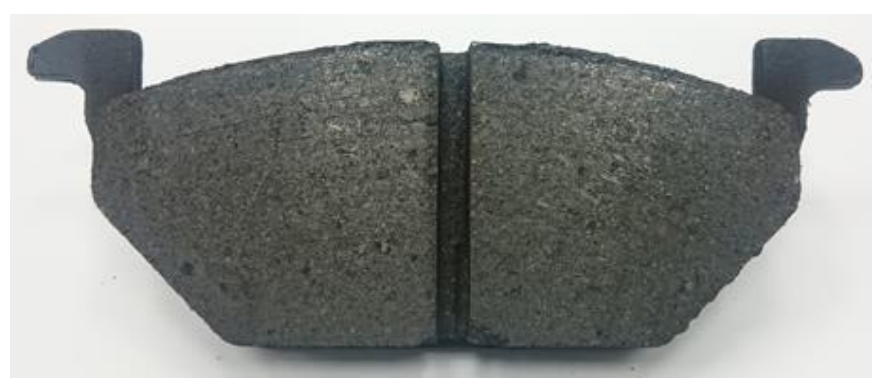

Picture. 12. The Slotted brake pad after the test

The comparison of friction coefficient values form the whole test is shown in table number 8 and graph number 5 .

Tab. 8. Final test results.

\begin{tabular}{|l|c|c|c|}
\hline Test sample & Stock & Chamfer & Slot \\
\hline MIN $\mu$ & 0.264 & 0.266 & 0.288 \\
\hline MAX $\mu$ & 0.617 & 0.592 & 0.567 \\
\hline AVERAGE $\mu$ & 0.435 & 0.427 & 0.416 \\
\hline Dispersion & 0.353 & 0.326 & 0.279 \\
\hline
\end{tabular}

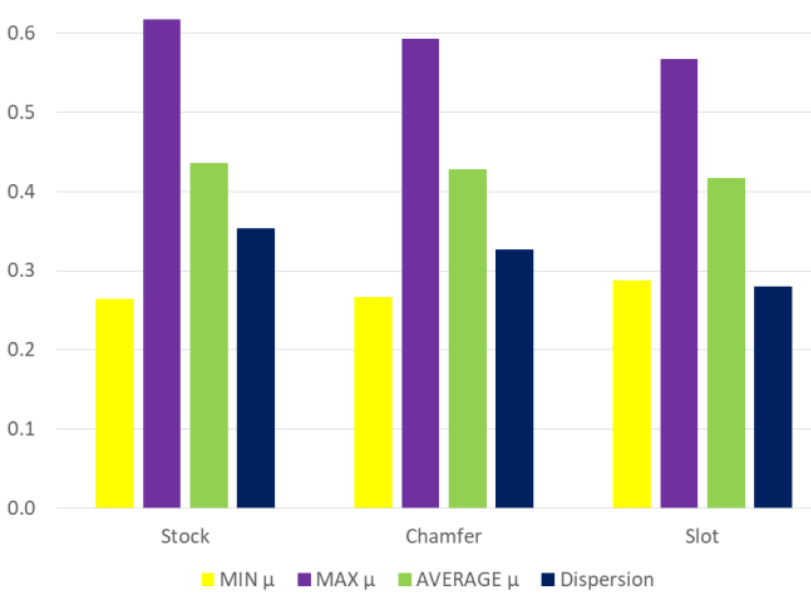

Graph. 5. Final friction coefficient test results comparison.

\section{SUMMARY}

The purpose of the article was to check the influence of making a machining and finishing modifications of brake pads on their friction characteristics. It looks like modifying brake pads surface apart from reducing squeal noise emission does have an effect on their friction characteristics. Both chambers and slots have improved brake pads performance. The modifications have reduced the maximum and average friction coefficient but it has increased the minimum friction coefficient values and reduced the disparity in maximum and minimum values. Although the modifications have decreased maximum friction coefficient values, they made it more stable and settled and that is more important because makes the brake more predictable, flexible and dependable. Modified brake pads have more stable friction coefficient in low and high temperature and high speed and deceleration braking conditions. The difference in the friction coefficient for various braking applications conditions is smaller for modified pads, unmodified pads have this disparities a lot larger, and that is not beneficial because when the vehicle driver gets used to certain brake behaviour in certain braking conditions for a long time, he might be surprised when conditions will change and the brakes will lack friction coefficient, in effect he might have to use more brake pedal input in order to increase brake fluid pressure in order to increase the vehicles deceleration rate. This might be surprising for some unexperienced drivers and if happened suddenly might cause a potentially dangerous road situation. In conclusion modifying brake pads friction surface has a positive effect on their friction characteristics and it is strongly recommended to apply them to brake pads.

The brake pads modification influence on brakes friction characteristics and their influence on vehicle safety needs more research so this will be a topic of further author's research.

\section{BIBLIOGRAPHY}

1. B. Breuer, K. H. Bill, "Brake Technology Handbook", 1nd eng. ed., Warrendale, Pennsylvania, USA, SAE, 2008.

2. R. Limpert, "Brake Design and Safety", 3rd ed., Warrendale, Pennsylvania, USA, SAE, 2011

3. K. Reif, "Brakes, Brake Control and Driver Assistance Systems", Weisbaden, Germany, Springer Vieweg, 2014

4. B. Breuer, U. Dausend, "Advanced Brake Technology", 1nd eng. ed., Warrendale, Pennsylvania, USA, SAE, 2003.

5. S. F. Scieszka, "Hamulce cierne, zagadnienia materiałowe, konstrukcyjne i tribologiczne", 1st ed., Radom, Poland, WiZPITE, 1998

6. „Hamulce w pojazdach i maszynach roboczych”, Kraków, 1988.

7. J. Jaworski, „Okładziny cierne do hamulców i sprzęgieł pojazdów mechanicznych", WKiŁ, Warszawa, 1984.

8. Z. Osiński, „Sprzęgła i hamulce”, PWN, Warszawa, 2000.

9. Z. Szydelski, „Pojazdy samochodowe - sprzęgła, hamulce i przekładnie hydrokinetyczne", WKiŁ, Warszawa, 1981

\section{The influence of the brake pad surface machining and finishing on its friction performance - examined by inertia brake dynamometer testing}

The article describes the influence of brake pads surface machining and finishing on their friction characteristics. It shows the methods of machining and finishing of the brake pads surface and their influence on noise emission and performance. It shows the brake dynamometer test results obtained on three brake pads which have three different type of surface modification and their detailed analysis and comparison.

\section{Authors:}

mgr inż. Tomasz Dąbrowski - BOSMAL Automotive Research and Development Institute, Car Assemblies Testing Department, Mechanical Testing Laboratory, Brake System Testing Laboratory.

dr inż. Dariusz Kurczyński - Kielce University of Technology, Faculty of Mechatronics and Machinery Design, Department Automotive Engineering and Transport.

dr inż. Piotr Łagowski-Kielce University of Technology, Faculty of Mechatronics and Machinery Design, Department Automotive Engineering and Transport.

mgr inż. Michał Warianek- Kielce University of Technology, Faculty of Mechatronics and Machinery Design, Department Automotive Engineering and Transport.

JEL: R41, L62 DOI: 10.24136/atest.2018.101

Data zgłoszenia: 2018.05.22 Data akceptacji: 2018.06.15 